\title{
Right coronary artery perforation
} extending to the coronary sinus of Valsalva during percutaneous intervention successfully sealed with polytetrafluoroethylene-covered stent: a case report

\author{
Sahela Nasrin ${ }^{1}$, Fathima Aaysha Cader ${ }^{1,2^{*}}$, M. Maksumul Haq ${ }^{1}$ and Md. Rezaul Karim
}

\begin{abstract}
Background: Right coronary artery perforation extending to the sinus of Valsalva is a rare and potentially fatal complication of percutaneous coronary intervention. There are no definite guidelines on the management strategies for such complications. Treatment modality depends on the patient's haemodynamic stability and the extent of aortic involvement. Polytetrafluoroethylene-covered stents have emerged as a revolutionary strategy, enabling efficient endovascular repair of the entry port of such dissections, particularly the coronary ostia, and obviating the need for high-risk emergent surgical intervention.
\end{abstract}

Case presentation: A 60 year old Bangladeshi gentleman underwent a coronary angiogram following a prior inferior ST elevation myocardial infarction (MI), 1 month previously. Coronary angiography done via right radial approach using 5 FRTIG catheter showed diffuse mid RCA disease with maximum 90\% stenosis. Angioplasty of the RCA was planned. The RCA was cannulated with a 6-French JR 3.5 guiding catheter (USA). The lesion was crossed by a 0.014 inch guide wire and stented with a $2.75 \times 38 \mathrm{~mm}$ novolimus-eluting DESyne stent, after predilatation. Immediately after stenting, a Type II perforation was observed in the ostial RCA, which progressed into the right coronary sinus of Valsalva. As the patient was haemodynamically stable with no ischaemia on ECG, we attempted to seal the ostial RCA with bare metal stents. Two successive bare metal stents failed to seal the aorto-coronary dissection. Ultimately, a $3.0 \times 19 \mathrm{~mm}$ polytetrafluoroethylene-covered stent was deployed to seal the entry port in the ostial RCA, yielding a satisfactory angiographic result with only minimal contrast staining limited to the right sinus of Valsalva. The patient was closely monitored and discharged on dual antiplatelet therapy comprising of aspirin and prasugrel. He remained asymptomatic and with follow up echocardiograms showing no pericardial effusion nor extension of the dissection.

Conclusions: The polytetrafluoroethylene-covered stent provides a safe and effective means of sealing iatrogenic aorto-coronary dissections complicated by Ellis type II or II perforations, thus avoiding emergency surgery. However, as they are associated with increased incidence of stent thrombosis, an efficient and prolonged post- $\mathrm{PCl}$ antiplatelet regimen is recommended.

Keywords: Coronary artery perforation, Sinus of Valsalva, Covered stent

\footnotetext{
*Correspondence: aaysha.cader@gmail.com

${ }^{1}$ Department of Cardiology, Ibrahim Cardiac Hospital \& Research Institute

(ICHRI), Dhaka, Bangladesh

Full list of author information is available at the end of the article
} 


\section{Background}

Iatrogenic right coronary artery (RCA) perforation with extension to the sinus of Valsalva is a rare but potentially life-threatening occurrence during coronary angiography and percutaneous coronary intervention (PCI) [1-6]. Although it may sometimes be difficult to discern between coronary perforation and dissection [7], aortocoronary dissection is usually diagnosed with angiography showing a persistently localised dye staining within the sinus of Valsalva or extension into the aorta $[1,8]$. The gravity of this event hinges on the fact that it could lead to acute occlusion of the relevant coronary artery, in addition to the danger of dissection extending to the ascending aorta and further, if not immediately sealed [3].

This potentially fatal complication is often the result of a coronary artery dissection or perforation providing the entry door for subsequent retrograde progression into the sinus of Valsalva [9]. In the vast majority of cases, it involves percutaneous procedures of the RCA $[1-7$, 9-22].

Treatment remains challenging, as prompt institution of management is paramount to avoiding fatal outcome. Options include urgent surgical intervention, placement of an intracoronary stent at the origin of the culprit vessel, or conservative treatment $[2,3,10]$. Limited aortocoronary dissections have been successfully managed by stent implantation with good coverage to the ostium of the perforated/dissected vessel [1-3, 5-7, 15, 16, 19, 22]. In the modern era, polytetrafluoroethylene (PTFE) covered stents have emerged as a revolutionary strategy to seal the entry site, particularly in cases of perforation $[6$, $7,10,23-26]$. They are also associated with better long term outcome and prognosis. More extensive involvement of aortic root and/or ascending aorta requires surgical intervention, and is associated with poor prognosis $[3,4,12,16]$. We report a case of aorto-coronary dissection during PCI, which resulted from extension of a type II perforation of RCA into the Sinus of Valsalva. It was successfully managed with a covered stent, without surgical intervention, resulting in optimal coronary blood flow and diminution of the aortic dissection.

\section{Case presentation}

A 60-year-old normotensive, non-diabetic Bangladeshi male underwent an elective CAG with the indication of unstable angina. He had a history of Inferior ST elevation myocardial infarction (MI), thrombolysed with Streptokinase 1 month earlier at a state tertiary care institute.

Physical examination was unremarkable. Electrocardiography (ECG) showed pathological Q and $\mathrm{T}$ inversions in the inferior leads (II, III, aVF) indicative of a prior inferior MI. Trans-thoracic echocardiogram (TTE) revealed a left ventricular ejection fraction (EF) of $50 \%$ with inferior wall hypokinesia. All blood investigations were normal including renal parameters. He was on aspirin, clopidogrel, bisoprolol, nitroglycerine, trimetazidine and atorvastatin.

He was given a pre-procedural antiplatelet load of $600 \mathrm{mg}$ clopidogrel and CAG was done via right radial approach using 5 FR radial TIG catheter (Terumo). Angiographic procedure was uncomplicated and revealed a dominant RCA and diffuse mid RCA disease with maximum 90\% stenosis (Fig. 1). Left anterior descending (LAD) artery and 2nd obtuse marginal (OM2) artery had mild and moderate disease respectively.

Following CAG, he was selected for angioplasty of the RCA. The RCA was easily cannulated with a soft tipped 6-French JR 3.5 guiding catheter (USA). After the selection of the guiding catheter in the RCA, a 0.014 in. Asahi Sion Blue PTCA guide wire (Asahi Intecc Co., Ltd., Japan) was advanced to cross the lesion. Pre-dilatation was done by $2.5 \times 15 \mathrm{~mm}$ Sapphire balloon at an inflation pressure of 12 atmospheres (ATM) for $10 \mathrm{~s}$. Stenting was done by $2.75 \times 38 \mathrm{~mm}$ novolimus-eluting DESyne stent (Elixir medical corporation, Sunyvale, CA) at 16 ATM for $20 \mathrm{~s}$, with restoration of thrombolysis in myocardial infarction (TIMI) III flow. At this point we observed an Ellis type II perforation in the ostial RCA, as evidenced by subtle contrast (Fig. 2; Additional file 1: Video S1). The next contrast injection given very gently showed that the perforation had extended into the right coronary sinus of Valsalva, as evidenced by contrast dye beyond the RCA ostium and retrograde stasis limited to the sinus of Valsalva (Fig. 3; Additional file 2: Video S2). There was no rupture of the balloon. Despite coronary perforation, the patient remained haemodynamically stable, reported no

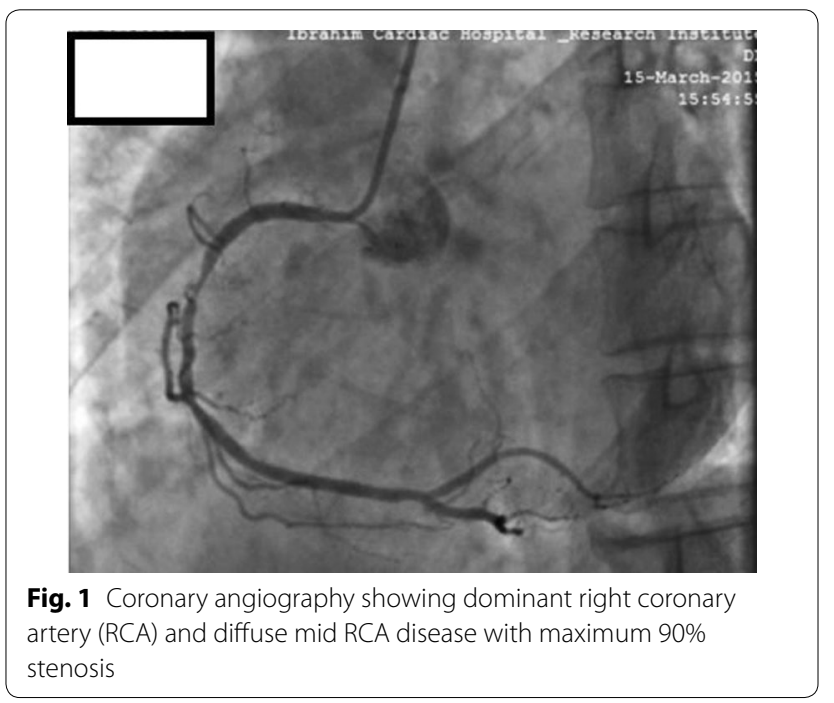




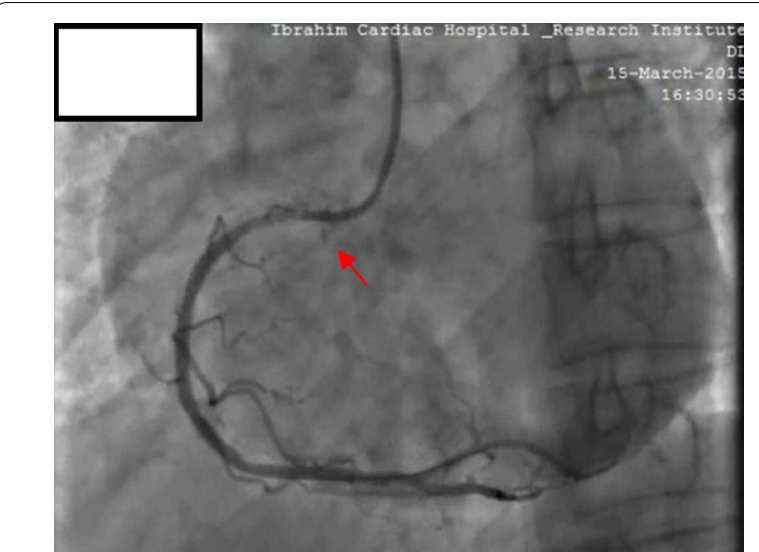

Fig. 2 Coronary angiography following stenting of RCA lesion. Stenting was done by $2.75 \times 38 \mathrm{~mm}$ novolimus-eluting DESyne stent at 16 ATM for $20 \mathrm{~s}$, with restoration of thrombolysis in myocardial infarction (TIMI) III flow. An Ellis type II perforation is noted in the ostial RCA, evidenced by subtle contrast (red arrow)

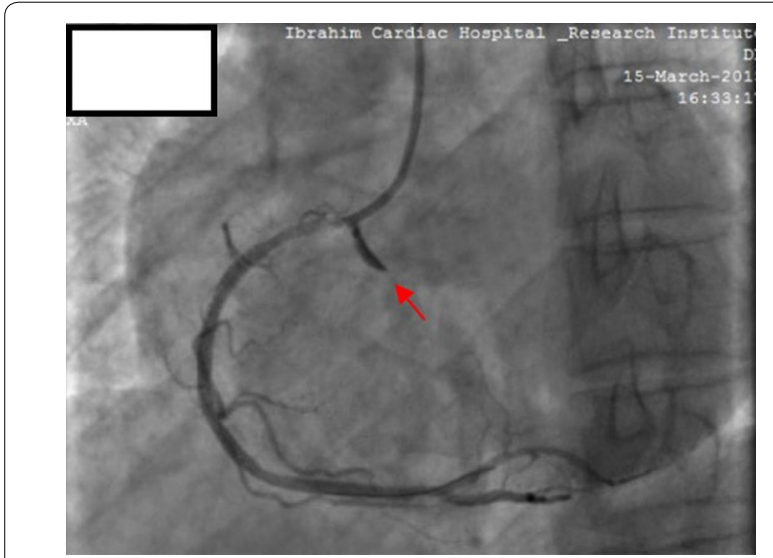

Fig. 3 Coronary angiography following the next contrast injection showing extension of RCA perforation into the right coronary sinus of valsalva (red arrow)

chest discomfort and electrocardiogram showed no sign of new ischemia. Urgent cath lab TTE showed no pericardial effusion or aortic regurgitation (AR). Serum cardiac enzymes and troponin I were within normal range.

An attempt to seal the perforation in the ostial RCA was made with a $3.0 \times 23 \mathrm{~mm}$ bare metal stent (BMS) (Genius Magic Eurocor GmbH stent (Germany) (Cobalt chromium coronary stent system), which was deployed in proximal overlap of the previous stent, to obtain adequate coverage of the RCA ostium (Fig. 4). Despite this, as the dissection persisted, another $3.0 \times 12 \mathrm{~mm}$ BMS (Avantgarde stent Cobalt chromium coronary stent system) was deployed, covering the ostium of RCA, but with no satisfactory result (Fig. 5).

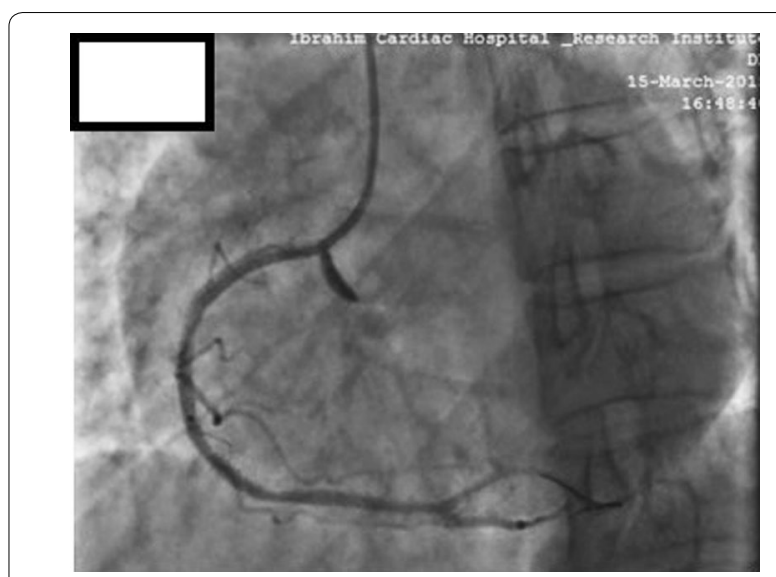

Fig. 4 Coronary angiography after implantation of bare metal stent in an attempt to seal the perforation showing persistence of contrast within the sinus of Valsalva. A Genius Magic Eurocor GmbH stent (Germany) Cobalt chromium coronary stent system was deployed in proximal overlap of the previous stent, to obtain adequate coverage of the RCA ostium

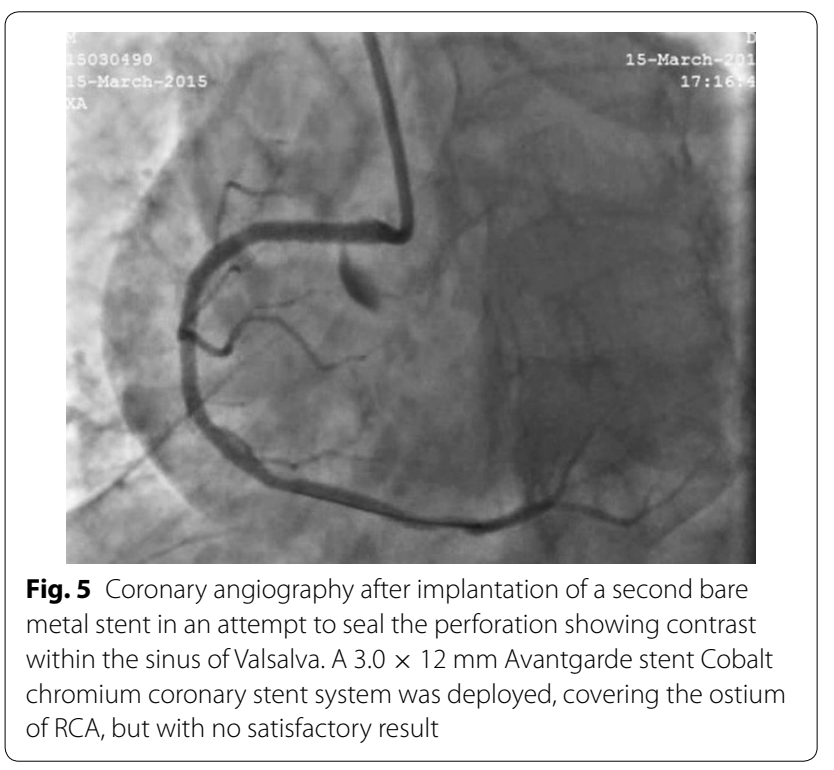

Ultimately, a $3.0 \times 19 \mathrm{~mm}$ PTFE-covered stent (Graftmaster RX Coronary Stent Graft System, Abbott Vascular, USA) was deployed in proximal overlap to include complete coverage of the ostial RCA, which was considered the entry point of the aortic dissection. The next control injection demonstrated satisfactory sealing of the coronary perforation with only minimal contrast staining limited to the right sinus of Valsalva. The RCA presented a good angiographic result with TIMI Grade III flow (Fig. 6; Additional file 3: Video S3). A final cine run taken 30 min later showed a faintly opacified coronary sinus and no further extension into the aortic root. 


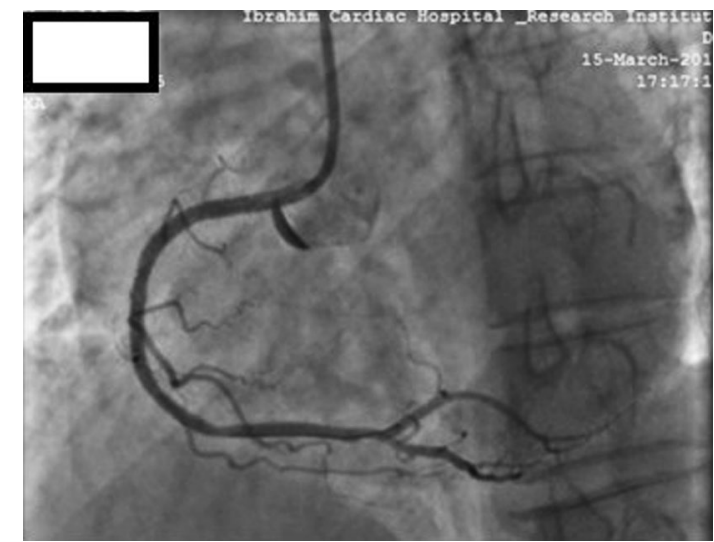

Fig. 6 Coronary angiography after implantation of PTFE-covered stent showing minimal contrast staining limited to the right sinus of Valsalva. A 3 × 19 mm Graftmaster RX Coronary Stent Graft System, Abbott Vascular, USA was deployed in proximal overlap to include complete coverage of the ostial RCA with good angiographic result and TIMI Grade III flow

As the patient experienced no chest pain or ischaemia, the procedure was concluded and he was monitored in the coronary care unit $(\mathrm{CCU})$, where he remained haemodynamically stable throughout. Follow up TTE done daily showed no signs of pericardial effusion, AR or further progression of the dissection. He had an uneventful post-catheterisation period and was discharged 2 days later on dual antiplatelet therapy (DAPT) of aspirin and prasugrel, in addition to anti-ischaemic medications. The patient was asymptomatic at 2 -week and subsequent follow up at 2 months, and TTE showed no pericardial effusion.

\section{Discussion and conclusions}

Despite its infrequent incidence, aorto-coronary dissection involving the sinus of Valsalva is potentially catastrophic, leading to devastating consequences [3-6, 11, $13,20,21,27]$. The first case of aortic dissection as a complication of PCI was described by Moles et al. [4]. As in our case, the majority (i.e. $>80 \%$ ) of such cases have arisen secondary to RCA dissection or perforation [1-7, 9-22, 27], usually the proximal or ostial RCA [8]. This could be due to differences in the histologic structure of the ostia of RCA and left main coronary artery (LMCA) $[1,8,12,18]$. The periostial and sino tubular junctions of LMCA are formed by more concentrically arranged circular and spiral smooth muscle cells in its intima, with abundant elastic fibres than the RCA, which explains the LMCA's greater resistance to retrograde dissection) $[1,8$, 12, 18].

In the pre-stent era, dissection of sinus of Valsalva was reported secondary to prolonged balloon inflation, associated with rupture of the balloon [3, 22]. With the advent of PCI and stenting, the mechanisms for iatrogenic perforation are being attributed to: aggressive manipulation of rigid wires into subendothelial spaces, when attempting to re-canalise tight lesions [3, 11, 12 , $14,16,19,22]$; forceful manipulation of guiding catheters that are either wedged [17] or in a non-coaxial position relative to the proximal segment of the coronary artery $[2-4,6,8,10-15,17,18,20,22,27,28]$; and prolonged balloon inflations $[3,12]$. A vigorous manual injections of contrast medium into the subintimal space plays a major role in extending the dissection further, by generating reverse flow proximal to the catheter tip and causing retrograde extension $[3,4,8,11,14,15,17-19,21,28]$.

Perhaps the greatest risk for PCI-related dissections is the presence of heavily calcified vessels or chronic total occlusions (CTO) [13, 22], which require more aggressive catheter manipulation for better support, and the usage of stiff wires in vessels whose walls are less resistant to trauma [1, 2, 8, 11, 14-16]. Hydrophilic coated guide wires are associated with increased risk of coronary perforation [7, 21, 26, 29], due to low coefficient of friction and ease of distal migration [29]. Amplatz catheters are more frequently associated with ostial coronary artery dissections $[2,7,15,21]$. Some reports have also demonstrated the involvement of JR catheters in dissection [1, $2,7]$.

A recent $\mathrm{MI}$, as in our patient, poses additional risk, as the inflammatory process of infarcted vessels render them tender, with tendency to dissection $[1,2]$. Iatrogenic dissections are more common in the setting of acute MI (0.19\%), than for non-acute MI interventions (0.01\%) [2]. Cystic medial necrosis [3, 11, 17], smaller RCA size [2], arterial hypertension and age $>60$ years are additional risk factors [1].

In our case, mechanical trauma caused by guide catheter manipulation during its withdrawal seems the most likely culprit for causing the port for further dissection: shearing forces of blood flow during systole or diastole may have assisted the propagation of the ostial perforation to involve the sinus of Valsalva [1.4.21]. Even vigorous inspiration by the patient during contrast injection could pose a risk [30] as in our patient. Moreover, he was restless throughout the procedure, repeatedly attempting to observe it, in spite of strong counselling against doing so.

Once the dissection was noted, vigorous contrast injections were avoided and further stenting was done with gentle manipulations of guide catheter and wires. Rapid recognition of the patient's haemodynamic conditions [20] and urgent assessment by TTE or trans-oesophageal echocardiography (TOE) in the cath lab [14] is paramount to deciding treatment modality, which also 
depends on the extent of aortic involvement and underlying coronary anatomy $[2,5,16]$.

In our case, there was an Ellis type II perforation in the proximal RCA which extended into the ostium and further into the sinus of Valsalva. Ellis et al. defined the angiographic classification of coronary perforations, describing type II perforations as pericardial or myocardial blush without $\mathrm{a} \geq 1 \mathrm{~mm}$ exit hole [31]. Type I and type II perforations are usually confirmed by retrospective review of the angiogram, and can be easily missed if not looked for [7].

Localised dissections are usually contained below the sino-tubular junctions, by the well-developed supravalvular ridge, and believed to resolve spontaneously in the first month $[1,3,8]$. However, despite some successful outcomes [8,13, 20,32], localised dissections treated conservatively have sometimes rapidly progressed to extensive aortic dissection [3,18, 22], with some even subsequently requiring surgical intervention $[1,3,4]$.

Thus, immediate percutaneous stenting of the perforated ostium and sealing the presumed site of entry door for aorto-coronary dissection, is the preferred modality in haemodynamically stable and localised dissections (with suitable anatomy for stenting) [1, 5, 6, 12, 19, 22]. Bae et al. reported the first case of aorto-coronary dissection successfully treated with PTCA and stenting, without an operation [19].

Previously, bare metal stents were preferred, owing to their delivery ability in the ostium $[11,13,16]$. Some operators have deployed drug-eluting stents (DES) [11, 21]. However, the presence of cells in a standard stent may not fully cover the site of entry of the dissection [6]. Thus, in free perforations causing a large entry port at the coronary ostium, stent grafts or covered stents are more effective $[8,15]$, as they prevent contact between vessel wall and components of blood, acting as a mechanical barrier [6, 33, 34]. Successful coronary stenting seals off the entry port within minutes of the complication developing, thus preventing further propagation of aortic dissection $[1,3,6,8,21]$.

Abu-Ful et al. reported the first case in which acute aortic dissection complicating PCI was treated with a covered stent to seal the entry site [6], a strategy that was later adopted by others [7, 10]. The Graftmaster covered stent comprises of an expandable PTFE graft material sandwiched between two coaxially aligned stainless steel stents $[6,33]$. They are ideally suited to fully cover and seal entry sites formed by the coronary ostium itself, where standard stents maybe insufficient $[6$, 33]. However, as they are bulky with low flexibility and high profile, delivery may be difficult, and high-pressure deployment and/or IVUS-guided optimisation has been recommended [13, 24, 33].
PTFE stents are associated with increased incidence of subacute stent thrombosis higher than in standard stents, estimated at 5.7 to $8.6 \%[23,33,34]$ and can occur later than with conventional stents. Increased incidence of restenosis and target lesion intervention is also reported $[7,33,34]$. These have been attributed to increased thrombogenicity and delayed endothelialisation of these stents [23, 26], thus warranting an extended duration of DAPT of at least 6 months to 1 year [24, 26, 34, 35]. Prasugrel or ticagrelor are suitable antiplatelet agents of choice, due mainly to their lack of intrinsic resistance [23, 35].

Once the dissection is stabilized, careful monitoring with optimum BP control and non-invasive imaging techniques, preferably in a coronary care unit setting is required, to detect progression of the dissection and ensuing complications. This can be accomplished by serial TTE/TOE, CT or MRI scan [3, 11, 12, 16, 18]. TOE/TTE appears to be superior to CT in the follow up of patients [1]. TOE has also been recommended instead of angiography [3]. If extension of the dissection is demonstrated, surgical repair should be considered [12].

This case demonstrates the greater efficacy of covered stents over bare metal stents, in immediate sealing of coronary ostium, thus limiting aorto-coronary dissections localised to the sinus of Valsalva. In addition to minimal adverse effects, covered stents also circumvents the additional risks otherwise posed by the alternative option, which is surgical intervention and are associated with better prognosis [22]. However, appropriate treatment modalities should be reviewed on a case-by-case basis, particularly taking into account the patient's haemodynamic conditions and coronary lesion morphology.

\section{Additional files}

Additional file 1: Video S1. Coronary angiography following stenting of RCA lesion. Stenting was done by $2.75 \times 38 \mathrm{~mm}$ novolimus-eluting DESyne stent at 16 ATM for $20 \mathrm{~s}$, with restoration of thrombolysis in myocardial infarction (TIMI) III flow. An Ellis type II perforation is noted in the ostial RCA, evidenced by subtle contrast.

Additional file 2: Video S2. Coronary angiography following the next contrast injection after Ellis type II perforation. Angiography showing further extension of RCA perforation into the right coronary sinus of Valsalva.

Additional file 3: Video S3. Coronary angiography after implantation of PTFE-covered stent. There is significant of reduction contrast staining of the right coronary sinus of Valsalva following covered stent implantation.

\footnotetext{
Abbreviations

RCA: right coronary artery; CAG: coronary angiography; $\mathrm{PCl}$ : percutaneous coronary intervention; PTFE: polytetrafluoroethylene; MI: myocardial infarction; ECG: electrocardiogram; TTE: tran-thoracic echocardiography; EF: ejection fraction; LAD: left anterior descending; OM: obtuse marginal; ATM: atmospheres; TIMI: thrombolysis in myocardial infarction; BMS: bare metal stent; CCU: coronary care unit; DAPT: dual antiplatelet therapy; LMCA: left main coronary artery; CTO: chronic total occlusion; TOE: trans oesophageal echocardiography; DES: drug eluting stent.
} 


\section{Authors' contributions}

SN and FAC were responsible for original manuscript design and draft and the acquisition of data. SN, MMH and MRK were involved in direct patient care and emergency cath lab intervention. FAC and MS were involved in postcatheterisation patient management. MMH was involved in revision of the manuscript for important intellectual content. All authors read and approved the final manuscript.

\section{Author details}

1 Department of Cardiology, Ibrahim Cardiac Hospital \& Research Institute (ICHRI), Dhaka, Bangladesh. ${ }^{2}$ National Institute of Cardiovascular Diseases, Dhaka, Bangladesh.

\section{Acknowledgements}

The staff at the cardiac catheterisation laboratory of Ibrahim Cardiac Hospital \& Research Institute, Dhaka, Bangladesh.

\section{Competing interests}

The authors declare that they have no competing interests.

\section{Availability of data and materials}

All data generated or analysed during this study are included in this published article [and its additional files].

\section{Consent for publication}

Written informed consent for the publication was obtained from the patient for publication of this case report and any accompanying images. A copy of the written consent is available for review by the Editor-in Chief of this journal.

\section{Ethics approval and consent to participate}

Not applicable.

\section{Funding}

Not applicable.

\section{Publisher's Note}

Springer Nature remains neutral with regard to jurisdictional claims in published maps and institutional affiliations.

Received: 2 May 2017 Accepted: 24 October 2017

Published online: 30 October 2017

\section{References}

1. Yip HK, Wu CJ, Yeh KH, Hang CL, Fang CY, Hsieh KY, Fu M. Unusual complication of retrograde dissection to the coronary sinus of Valsalva during percutaneous revascularization: a single-center experience and literature review. Chest. 2001;119(2):493-501.

2. Dunning DW, Kahn JK, Hawkins ET, O'Neill WW. latrogenic coronary artery dissections extending into and involving the aortic root. Catheter Cardiovasc Interv. 2000;51(4):387-93.

3. Perez-Castellano N, Garcia-Fernandez MA, Garcia EJ, Delcan JL. Dissection of the aortic sinus of Valsalva complicating coronary catheterization: cause, mechanism, evolution, and management. Cathet Cardiovasc Diagn. 1998:43(3):273-9.

4. Moles VP, Chappuis F, Simonet F, Urban P, De La Serna F, Pande AK, Meie B. Aortic dissection as complication of percutaneous transluminal coronary angioplasty. Cathet Cardiovasc Diagn. 1992;26(1):8-11.

5. Li L, Cao Y. Extensive dissection to the coronary sinus of Valsalva during percutaneous intervention in right coronary artery - a case report and literature review. Clin Med Insights Cardiol. 2011;5:41-4.

6. Abu-Ful A, Weinstein JM, Henkin Y. Covered stent: a novel percutaneous treatment of iatrogenic aortic dissection during coronary angioplasty. J Invasive Cardiol. 2003;15(9):408-9

7. Lin P-L, Tsai J-P, Wang K-T, Sun T-K, Yeh H-I, Hou CJ-Y. An experience of catheter-induced aortocoronary dissection complicated by subtle coronary perforation. Acta Cardiol Sin. 2008:24:164-8.
8. Bryniarski L, Dragan J, Dudek D. Dissection of the right coronary ostium and sinus of Valsalva during right coronary artery angioplasty. J Invasive Cardiol. 2008:20:E277-80.

9. Mauser M, Ennker J, Fleischmann D. Dissection of the sinus valsalvae aortae as a complication of coronary angioplasty. Z Kardiol. 1999;88(12):1023-7.

10. Huang S-Y, Chou P-C, Huang $\mathrm{C}-\mathrm{H}$, Chen PH. latrogenic aortocoronary dissection successfully treated with a covered stent. Fu-Jen J Med. 2008;6(1):47-52.

11. Alfonso F, Almería C, Fernández-Ortíz A, Segovia J, Ferreirós J, Goicolea J, Hernández R, Bañuelos C, Gil-Aguado M, Macaya C. Aortic dissection occurring during coronary angioplasty: angiographic and transesophageal echocardiographic findings. Cathet Cardiovasc Diagn. 1997:42(4):412-5

12. Goldstein JA, Casserly IP, Katsiyiannis WT, Lasala JM, Taniuchi M. Aortocoronary dissection complicating a percutaneous coronary intervention. J Invasive Cardiol. 2003;15(2):89-92.

13. Doyle $B$, Juergens CP. Conservative management of ascending aortic dissection caused by percutaneous coronary intervention. J Invasive Cardiol. 2004;16(2):92-4.

14. Boyle AJ, Chan M, Dib J, Resar J. Catheter-induced coronary artery dissection: risk factors, prevention and management. J Invasive Cardiol. 2006;18(10):500-3.

15. Oda H, Hatada K, Sakai K, Takahasi K, Miida T, Higuma N. Aortocoronary dissection resolved by coronary stenting guided by intracoronary ultrasound. Circ J. 2004;68(4):389-91.

16. Notaristefano S, Giombolini C, Santucci S, Fortunati F, Savino K, Notaristefano A, Ambrosio G. Successful treatment by percutaneous stent deployment of severe retrograde dissection of the right coronary artery extending into the sinus of Valsalva and ascending aorta. Int J Cardiol. 2005;104(1):112-4.

17. Pande AK, Gosselin G, Leclerc Y, Leung TK. Aortic dissection complicating coronary angioplasty in cystic medial necrosis. Am Heart J. 1996;131:1221-3.

18. Varma V, Nanda NC, Soto B, Roubin GS, Bajaj R, Jain S, Sanyal RS. Transesophageal echocardiographic demonstration of proximal right coronary artery dissection extending into the aortic root. Am Heart J. 1992:123(4 Pt 1):1055-7.

19. Bae JH, Kim KB, Kim KS, Kim YN. A case of aortocoronary dissection as a complication during a percutaneous transluminal coronary angioplasty (PTCA). Int J Cardiol. 1998;66(3):237-40.

20. Fiddler M, Avadhani SA, Marmur JD. Guide catheter-induced aortic dissection complicated by pericardial effusion with pulsus paradoxus: a case report of successful medical management. Case Rep Med. 2015;2015:480242.

21. Sekiguchi M, Sagawa N, Miyajima A, Hasegawa S, Yamazaki M, Kurabayashi M. Simultaneous right and left coronary occlusion caused by an extensive dissection to the coronary sinus of Valsalva during percutaneous intervention in right coronary artery. Int Heart J. 2009;50(5):663-7.

22. Carstensen S, Ward MR. latrogenic aortocoronary dissection: the case for immediate aortoostial stenting. Heart Lung Circ. 2008;17(4):325-9. https://doi.org/10.1016/j.hlc.2007.11.140 (Epub 2008 Feb 21)

23. Eeckhout E, Palma RD. Coronary perforation: an inconvenient complication. JACC: Cardiovasc Interventions. 2011;4(1):96-7.

24. Briguori C, Nishida T, Anzuini A, Di Mario C, Grube E, Colombo A Emergency polytetrafluoethylene-covered stent implantation to treat coronary ruptures. Circulation. 2000;102:3028-31.

25. Lansky AJ, Yang YM, Khan Y, Costa RA, Pietras C, Tsuchiya Y, Cristea E, Collins M, Mehran R, Dangas GD, Moses JW, Leon MB, Stone GW. Treatment of coronary artery perforations complicating percutaneous coronary intervention with a polytetrafluoroethylene-covered stent graft. Am J Cardiol. 2006;98(3):370-4 (Epub 2006 Jun 12)

26. Al-Mukhaini M, Panduranga P, Sulaiman K, Riyami AR, Deeb M, Riyami MB Coronary perforation and covered stents: an update and review. Heart Views. 2011;12(2):63-70. https://doi.org/10.4103/1995-705X.86017.

27. Jan AF, Habib S, Saghir T, Naseeb K. Guider induced coronary dissection with retrograde extension to aorta. Pak Heart J. 2010;43(3-4):60-3.

28. Ruda-Vega M. Aortic dissection-exceedingly rare complication of coronary angioplasty. Cathet Cardiovasc Diagn. 1997;42(4):416. 
29. Rogers JH, Lasala JM. Coronary artery dissection and perforation complicating percutaneous coronary intervention. J Invasive Cardiol. 2004;16(9):493-539.

30. Biel SI, Krone RJ. Left coronary artery dissection with an amplatz-shaped catheter. The role of vigorous inspiration during contrast injection. Chest. 1984;86:640-1.

31. Ellis SG, Ajluni S, Arnold AZ, Popma JJ, Bittl JA, Eigler NL, Cowley MJ, Raymond RE, Safian RD, Whitlow PL. Increased coronary perforation in the new device era. Incidence, classification, management, and outcome. Circulation. 1994;90(6):2725-30.

32. Carter AJ, Brinker JA. Dissection of the ascending aorta associated with coronary angiography. Am J Cardiol. 1994;73(12):922-3.
33. Campbell PG, Hall JA, Harcombe AA, de Belder MA. The Jomed Covered Stent Graft for coronary artery aneurysms and acute perforation: a successful device which needs careful deployment and may not reduce restenosis. J Invasive Cardiol. 2000;12(5):272-6.

34. Gercken U, Lansky AJ, Buellaesfeld L, Desai K, Badereldin M, Mueller R, Selbach G, Leon MB, Grube E. Results of the Jostent coronary stent graft implantation in various clinical settings: procedural and follow up results. Catheter Cardiovasc Interv. 2002;56(3):353-60.

35. Romaguera R, Waksman R. Covered Stents for Coronary Perforations: is there enough evidence? Catheter Cardiovasc Interv. 2011;78(2):246-53.

\section{Submit your next manuscript to BioMed Central and we will help you at every step:}

- We accept pre-submission inquiries

- Our selector tool helps you to find the most relevant journal

- We provide round the clock customer support

- Convenient online submission

- Thorough peer review

- Inclusion in PubMed and all major indexing services

- Maximum visibility for your research

Submit your manuscript at www.biomedcentral com/submit 